\title{
PENGEMBANGAN ANIMASI 3D TAMAN KOTA MENGGUNAKAN SOFTWARE SKETCHUP DAN LUMION
}

\author{
Nana Suarna', Ryan Hamonangan'), Mulyawan ${ }^{3)} \operatorname{Iin}^{4)}$ \\ ${ }^{1,2)}$ Program Studi Teknik Informatika STMIK IKMI Cirebon \\ J1 Perjuangan No 10B Kesambi Kota Cirebon \\ ${ }^{3)}$ Program Studi Rekayasa Perangkat Lunak STMIK IKMI Cirebon \\ Jl Perjuangan No 10B Kesambi Kota Cirebon \\ 4) Program Studi Komputerisasi Akuntansi STMIK IKMI Cirebon \\ Jl Perjuangan No 10B Kesambi Kota Cirebon \\ e-mail: $\underline{\text { st_nana@yahoo.com }}{ }^{1)}, \underline{\text { ryanhamoahmo1@gmail.com }}{ }^{2)}, \underline{\text { mulyawan22@gmail.com }}^{34)}$ \\ * Korespondensi : st_nana@yahoo.com
}

\begin{abstract}
ABSTRAK
Fungsi taman kota merupakan elemen estetika ruang kota, juga berfungsi sebagai elemen ekologi kota. Sebagai elemen ekologi kota, taman kota berfungsi sebagai penjaga dan pengatur iklim mikro. Selain itu, taman kota merupakan sarana umum yang ditata serta dibentuk untuk dapat dimanfaatkan oleh seluruh masyarakat kota sebagai sarana sosial. Dalam penelitian ini akan di rancang berbentuk animasi 3D dengan menggunakan metode pengembangan animasi 3d menggunakan software Sketchup dan Lumion menggunakan metode MDLC. Objek animasi 3D ini pilihan yang efektif untuk membuat animasi yang dapat dirotasi dan berpindah seperti objek riil. animasi 3D memiliki keunggulan dari segi kualitas bahan serta design yang menarik dan pelayanan yang baik. Dari kegiatan-kegiatan pembuatan media animasi 3D membuktikan perusahaan ini memiliki kreatifitas dan kualitas yang baik.Hasil penelitian tersebut dapat dinyatakan bahwa Perancangann animasi RTH dengan Sketchup dan lumnion Dapat mempermudah dalam perancangan RAB sebanyak 30\%.Dengan nilai t tabel. 1,699127 maka -t.tabel =-1,699127. Sedangkan t.hitung adalah $-7,803$. Karena nilai -t.tabel $(-1,699127)>$ t.hitung $(-7,803)$. Maka Ho ditolak Ha diterima
\end{abstract}

Kata Kunci: Ruang Terbuka Hijau (RTH), MDLC, Animasi, Sketchup, Lumnion.

\begin{abstract}
The function of a city park is an aesthetic element of urban space, it also functions as an ecological element of the city. As an ecological element of the city, city parks work as keepers and regulators of microclimate. In addition, the city park is a public facility which is organized and can be used by the whole community as a social facility. In this research, 3D animation will be designed using $3 D$ animation design method using Sketchup and Lumion software using MDLC method. This 3D animation object is an effective choice for creating animations that can be rotated and moved like real objects. 3D animation has advantages in terms of material quality as well as attractive design and good service. From the activities of making 3D animation media proving this company has creativity and good quality.The purpose of this research is to create 3D animated green space (Green Open Space) in Panjunan village. To make 3D animation so that the planning process of making green space space plan $(R A B)$ can be determined. To agree to get an RTH animation using Sketchup and Lumnion.
\end{abstract}

Keywords: Green Open Space (RTH), MDLC, Animation, Sketchup, Lumnion. 


\section{Pendahuluan}

\subsection{Latar Belakang Masalah}

Taman Kota adalah taman yang berada di lingkungan perkotaan dalam skala yang luas dan dapat mengantisipasi dampak-dampak yang ditimbulkan oleh perkembangan kota dan dapat dinikmati oleh seluruh warga kota. Tempat penyimpanan air tanah, sehingga mencegah datangnya banjir dan erosi serta menjamin pasokan air tanah. Ruang Terbuka Hijau (RTH) merupakan area yang memanjang berbentuk jalur dan atau area mengelompok, yang penggunaannya lebih bersifat terbuka, tempat tumbuh tanaman, baik yang tumbuh secara alamiah maupun yang sengaja di tanam[1][2].

Animasi sekarang ini banyak digunakan oleh pengembang bisnis properti untuk menunjukkan gambaran bentuk bangunannya kelak, seperti yang banyak dilihat di media elektronik, banyak pengembang ternama yang mengiklankan propertinya dalam bentuk video animasi untuk menunjukkan gambaran bagaimana bentuk dan fasilitas hunian itu nantinya[3][4]. Tidak hanya pada bisnis properti, kebutuhan umum milik publik seperti taman kota juga tidak terlepas dari pengunaan animasi untuk menunjukkan gambaran hasil taman itu nantinya[5].

Teknologi yang dapat digunakan untuk menciptakan suatu objek 3D sangatlah banyak, mulai dari piranti terbuka (Open Source) hingga komersil yang berbayar. Dengan diberikannya fitur-fitur yang memudahkan seorang animator untuk membuat dan mengolah suatu objek, seperti gerak, tekstur, dan audio menjadi satu kesatuan animasi[6].

Kata animasi itu sendiri sebenarnya penyesuaian dari kata animation yang berasal dari kata dasar to animate dalam kamus umum Inggris - Indonesia berarti menghidupkan. Animasi adalah untuk membuat sesuatu hidup, sebagian orang mengira bahwa animasi itu sama dengan motion (gerakan), tetapi animasi mencakup semua yang mengandung efek visual sehingga animasi mencakup perubahan posisi terhadap waktu, bentuk, warna, struktur, tekstur dari sebuah objek, posisi kamera, pencahayaan, orientasi dan fokus dan perubahan dalam teknik rendering. Secara umum animasi adalah suatu kegiatan menghidupkan, menggerakkan benda mati[7][8].

Pada jurnal [1] dijelaskan bahwa suatu benda mati diberikan dorongan kekuatan, semangat dan emosi untuk menjadi hidup dan bergerak atau hanya berkesan hidup.

Program Kota Tanpa Kumuh (Kotaku) adalah satu dari sejumlah upaya strategis Direktorat Jenderal Cipta Karya Kementerian Pekerjaan Umum dan Perumahan Rakyat untuk mempercepat penanganan permukiman kumuh di Indonesia Tujuan umum program ini adalah meningkatkan akses terhadap infrastruktur dan pelayanan dasar di permukiman kumuh perkotaan untuk mendukung perwujudan permukiman perkotaan yang layak huni, produktif, dan berkelanjutan. Dalam tujuan umum tersebut terkandung dua maksud. Pertama, memperbaiki akses masyarakat terhadap infrastruktur dan fasilitas pelayanan di permukiman kumuh perkotaan. Kedua adalah meningkatkan kesejahteraan masyarakat di perkotaan melalui pencegahan dan peningkatan kualitas permukiman kumuh, berbasis masyarakat, dan partisipasi pemerintah daerah.

Ruang terbuka hijau adalah area memanjang/jalur dan/atau mengelompok, yang penggunaannya lebih bersifat terbuka, tempat tumbuh tanaman, baik yang tumbuh secara alamiah maupun yang sengaja ditanam. Ruang terbuka hijau public merupakan ruang terbuka yang dimiliki dan dikelola oleh pemerintah daerah kota yang digunakan unutk kepentingan masyarakat secara umum. Yang termasuk ruang terbuka hijau public antara lain adalah taman kota, taman pemakaman umum, dan jalur hijau sepanjang jalan, sungai, dan pantai[9]. Yang termasuk ruang terbuka hijau privat antara lain adalah kebun halaman rumah/gedung milik mastarakat atau swasta yang ditanami tumbuhan. Proporsi 30 (tiga puluh) persen merupakan ukuran minimal untuk menjamin keseimbangan ekosistem kota, baik keseimbangan system hidrologi dan system mikrolimat, maupun system ekologis lain, yang selanjutnya aka meningkatkan fungsi dan proporsi ruang terbuka hijau di kota, pemerintah, masyarakat, dan swasta di dorong untuk me- 
nanam tumbuhan diatas bangunan miliknya. Proporsi ruang terbuka hijau public seluas minimal 20 (dua puluh) persen yang disediakan oleh pemerintah daerah kota dimaksudkan agar proporsi ruang terbuka hijau minimal dapat lebih dijamin pencapaiannya sehingga memungkinkan pemanfaatannnya secara luas oleh masyarakat (UU No.26, 2007 Tentang Penataan Ruang).

Dalam jurnal yang diterbitkan Sugiyanti Puji Lestari, Irwan Noor, Heru Ribawanto Pengembangan Ruang Terbuka Hijau (Rth) Dalam Upaya Mewujudkan Sustainable City.

Ruang Terbuka Hijau (RTH) merupakan solusi alternatif dalam mengantisipasi krisis lingkungan di masa depan. Penulisan ini bertujuan memberikan gambaran pengembangan RTH dalam mewujudkan sustainable city. Metode penulisan Deskriptif dengan tahap pertama menjelaskan pengembangan RTH, Kedua analisa pengembangan RTH dalam mewujudkan sustainable city dan ketiga menganalisis faktor pendorong dan penghambat menuju sustainable city. Hasil penelitian menunjukkan Kabupaten Nganjuk memenuhi Peraturan Perundangan No 26 tahun 2007 mengenai 30 persen RTH dengan melakukan pengembangan RTH Pertamanan, Hutan Kota, Jalur Hijau, Pekarangan, Pertanian dan Perkebunan yang memenuhi fungsi ekonomi, wisata, partisipatif serta keseimbangan lingkungan, dengan cara pemanfaatan ekosistem yang mampu tumbuh dan berkembang di kawasan Perkotaan Nganjuk. Pada pengembangan RTH menuju sustainable city terdapat beberapa faktor yang mempengaruhi yakni meliputi kondisi alam seperti tanah dan iklim, sistem organisasi, profesionalitas sumber daya manusia, serta kepentingan para stakeholder. Rekomendasi yang dapat diberikan meliputi pengembangan RTH berbasis Agribisnis, pengembangan RTH Budidaya tanaman, penguatan sistem pengawasan lingkungan dan pelimpahan wewenang pembangunan daerah pada daerah[2].

Pembangunan ruang terbuka hijau yang menyita anggaran dana Negara yang tidak sedikit jumlahnya, sering kali hasil yang didapatkan tidak seperti ekspektasi yang diharapkan. Hal ini terjadi karena sebelum pembangunan panitia pelaksana pembangunan tidak melakukan simulasi animasi 3D dari beberapa aspek arah estetika. Panitia pembangunan hanya melihat rencana pembangunan dari maket $3 \mathrm{~d}$ dan bentuk 2D aj, sehingga ketika pembangunan sudah selesai, hasil pembangunan tidak sesuai dengan harapan masyarakat. Hal ini ditunjukan dari hasil survey kepuasaan masyarakat dengan pembangunan RTH.

\section{METODE PENELITIAN}

\section{Metode Penelitian}

Tahapan-tahapan yang akan dilakukan dalam penelitian ini adalah sebagi berikut:

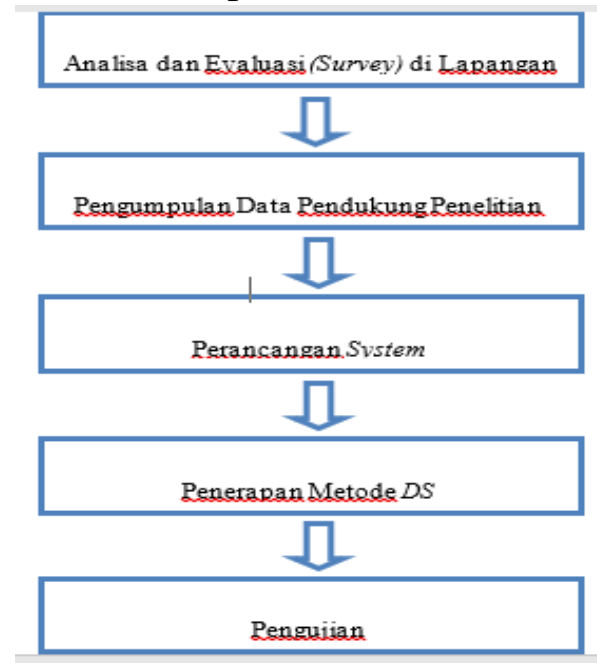

Gambar 1 Tahapan Pelaksanaan Penelitian 
Proses tahapan dalam penelitian ini meliputi :

1. Analisa survey dilapangan

Studi pustaka diperlukan sebelum atau bersamaan dengan survey lapangan dengan maksud ketika pengamat menemui kesulitan dilapangan, dapat mengacu ke teori yang telah dipelajari. Atau dapat dilakukan perbandingan kebenaran dari teori dengan kejadian nyata di lapangan. Survey lapangan dilakukan sebagai langkah awal untuk mengetahui kondisi aspek-aspek penting dalam mengevaluasi permasalahan banjir diwilayah Sungai Sragi Lama. Dengan survey lapangan diperoleh foto-foto yang merupakan gambaran RTH, proses pembuatan hingga hasil akhir yang diharapkan.

2. Pengumpulan data pendukung

1. Pengumpulan Data Primer

Sumber data primer ini diperoleh dari : Wawancara dengan peduduk sekitar dan instansi terkait tentang proses pembangunan suatu ruang terbuka hijau. Pengambilan gambar dan dokumentasi saat peninjauan secara langsung dilokasi.

2. Pengumpulan Data Sekunder

Sumber data sekunder ini diperoleh dari Dinas Cipta karya dan Tata Ruang. Adapun data-data sekunder yang diperoleh yaitu :

a. Peta kota Cirebon

- Skala $1: 200.000$

- peta wilayah pembangunan RTH

- RAB pembangunan RTH

- Hasil jajak pendapat rencana hasil RTH

1. Perancangan system

Sebelum melakukan penelitian, seorang peneliti harus melaksanakan beberapa persiapan yang terdiri dari, berikut ini ..

1. Tema/Topik Penelitian

2. Untuk memilih tema atau topik penelitian, seorang peneliti harus memiliki kepekaan terhadap kehidupan yang dihadapi. Seorang peneliti dapat memilih tema dari berbagai sumber seperti:

a) Fenomena sosial yang terjadi dalam kehidupan

b) Kajian kepustakaan

c) Informasi yang diberikan oleh pihak lain.

3. Mengidentifikasi Masalah

Pada tahap ini, seorang peneliti harus terlebih dahulu mencari apa masalah yang akan di teliti

4. Merumuskan masalah

Dalam tahapan ini, peneliti membuat rumusan masalah dari penemuan masalah yang ada berdasarkan masalah-masalah yang akan diteliti.

5. Mengadakan studi pendahuluan

Tahapan ini dilakukan untuk mengumpulkan informasi berkaitan dengan masalah yang akan diteliti, dengan begitu maka akan diketahui keadaan atau kedudukan masalah yang akan diteliti. Hasil yang didapat dari studi pendahuluan berguna untuk menyusun kerangka teoritis tentang pemecahan masalah dalam bentuk hipotesis yang akan di uji kebenarannya melalui pelaksanaan penelitian lapangan. Studi pendahuluan dapat dilakukan dengan melakukan studi dokumenter, kepustakaan dan studi lapangan.

6. Merumuskan hipotesis

Hipotesa merupakan dugaan sementara yang akan dibuktikan kebenarannya dari masalah yang sedang di teliti.

7. Menentukan sampel penelitian

Dalam tahapan ini merupakan untuk menentukan obyek yang akan diteliti. Keseluruhan obyek yang diteliti disebut sebagai populasi penelitian.

8. Menyusun rencana penelitian 
Tahap ini merupakan pedoman selama melaksanakan penelitian sebagai suatu pola perencanaan harus dapat mengungkapkan hal-hal yang berhubungan dengan kegiatan pelaksanaan penelitian yang memuat hal-hal berikut :

a) Masalah yang diteliti dan alasan mengapa melakukan penelitian

b) Bentuk atau jenis data yang dibutuhkan

c) Tujuan dilakukannya penelitian

d) Manfaat atau kegunaan penelitian

e) Dimana dilakukannya penelitian

f) Jangka waktu pelaksanaan penelitian

g) Organisasi kegiatan dan pembiayaan

h) Hipotesis yang di ajukan

i) Teknik pengumpulan dan pengolahan data

j) Sistematis laporan yang di rencanakan

k) Merumuskan alat penelitian

\section{Penerapan DS}

Domain DS berfokus pada aspek pengiriman teknologi informasi. Ini mencakup bidang-bidang seperti eksekusi aplikasi di dalam sistem IT dan hasil-hasilnya, serta, proses dukungan yang memungkinkan pelaksanaan yang efektif dan efisien dari sistem TI. Proses ini meliputi masalah keamanan dukungan dan pelatihan.

\section{Pengujian}

Pengujian sistem adalah pengujian program perangkat lunak yang lengkap dan terintegrasi. Perangkat lunak atau yang sering dikenal dengan sebutan software hanyalah satuan elemen dari sistem berbasis komputer yang lebih besar.Biasanya, perangkat lunak dihubungkan dengan perangkat lunak dan perangkat keras lainnya.

\section{HASIL DAN PEMBAHASAN}

\subsection{Spesifikasi Program}

Spesifikasi yang akan dijelaskan adalah animasi pemetaan kawasan, dan yang akan dibangun dengan kemampuan sebagai berikut:

a. Menampilkan informasi tentang pemetaan animasi kawasan ruang terbuka hijau (RTH).

b. Berupa video animasi kawasan.

c. Menampilkan detai tata ruang dan bangunan dalam suatu kawasan RTH.

\subsection{Spesifikasi Pengguna}

Animasi pemetaan kawasan RTH untuk mengefisienkan anggaran biaya ini ditujukan untuk digunakan oleh masyarakat, dan Dinas tata ruang kota Cirebon.

a. Sistem Operasi Windows 7 Ultimate

b. Skectup

c. Lumnion

d. Powerdirector

\subsection{Konsep perancangan}

Dalam penelitian perancangan animasi 3D taman kota ini konsep yang dibuat ialah suatu ruang terbuka hijau berupa taman yang berbentuk persegi panjang yang diperuntukkan bagi masyarakat kota untuk bersantai dan berkumpul, memiliki beberapa titik lokasi dalam satu taman untuk berkumpul bersama dan playzone untuk anak-anak. Serta memiliki suatu landmark yang menjadi tanda bahwa area tersebut merupakan pusat dari taman kota tersebut. 


\subsection{Desain(Design)}

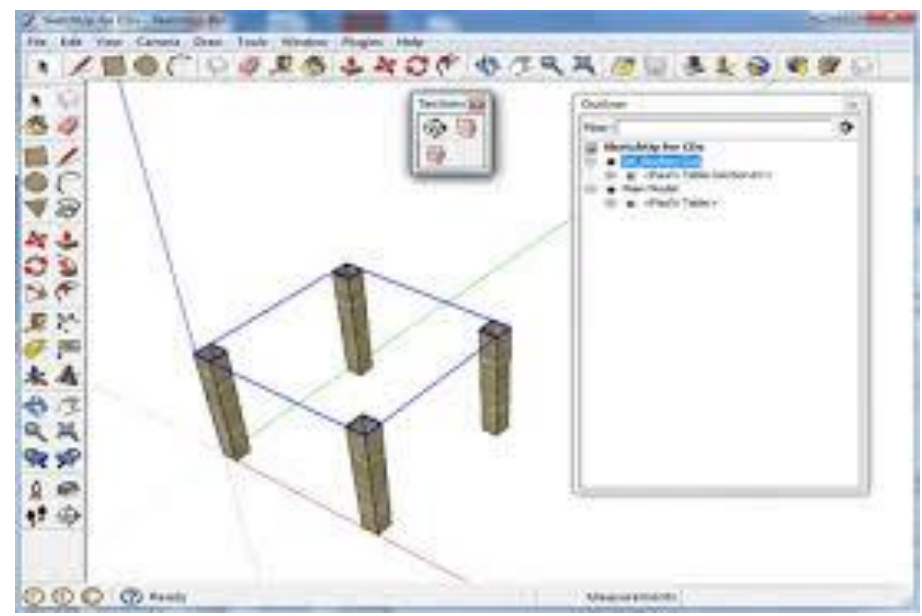

Gambar 2 Desain layout 2 dimensi

\subsection{Pengumpulan Material (Material Collecting)}

Dalam perancangan animasi taman kota ini penulis membutuhkan beberapa material tambahan yang diperlukan dalam perancangan animasi 3D taman kota ini. Material yang diperlukan disini yaitu gambar gambar yang nantinya akan dijadikan sebagai tekstur. Gambar yang dibutuhkan ialah gambar yang memiliki ekstensi .JPG, .PNG yang nantinya digunakan untuk memberikan tekstur pada objek-objek 3D yang akan dibuat. Material tekstur tersebut dapat diperoleh gratis dari situs google image ataupun yang disediakan secara default oleh software sketcup

\subsection{Merancang}

Pembuatan (Production) Produksi merupakan tahapan proses perancangan atau pembuatan animasi dalam penelitian ini. Tahapan ini dalam perancangan animasi adalah tahap produksi. Pada tahapan ini proses dibantu oleh software yang diperlukan dan dilakukan secara berurutan.

1. Pemodelan objek 3D Pemodelan objek 3D dibuat menggunakan perangkat lunak (software) sketchup dengan menggunakan beberapa bentuk objek dasar seperti, spline, box, cylinder, plane, dan pyramid untuk kemudian diubah menjadi editable poly dan dimodifikasi sesuai keinginan.

2. Pemodelan objek bangku Objek kaki bangku pada awalnya dibuat menggunakan tool berupa line untuk membuat bentuk dasarnya. Setelah dibuat bentuk dasar menggunakan line maka selanjutnya objek yang masih berbentuk garis tersebut diberikan modifikasi yang telah disediakan oleh Sketchup, yaitu extrudedan memberikan amount $=300$ untuk mengubahnya menjadi objek 3D

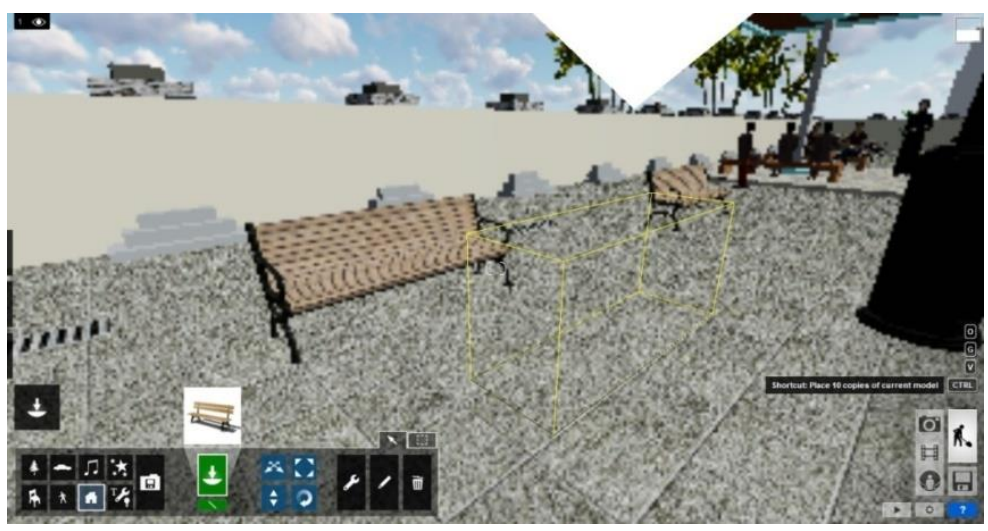

Gambar 3. Memberikan modifikasi extrude 


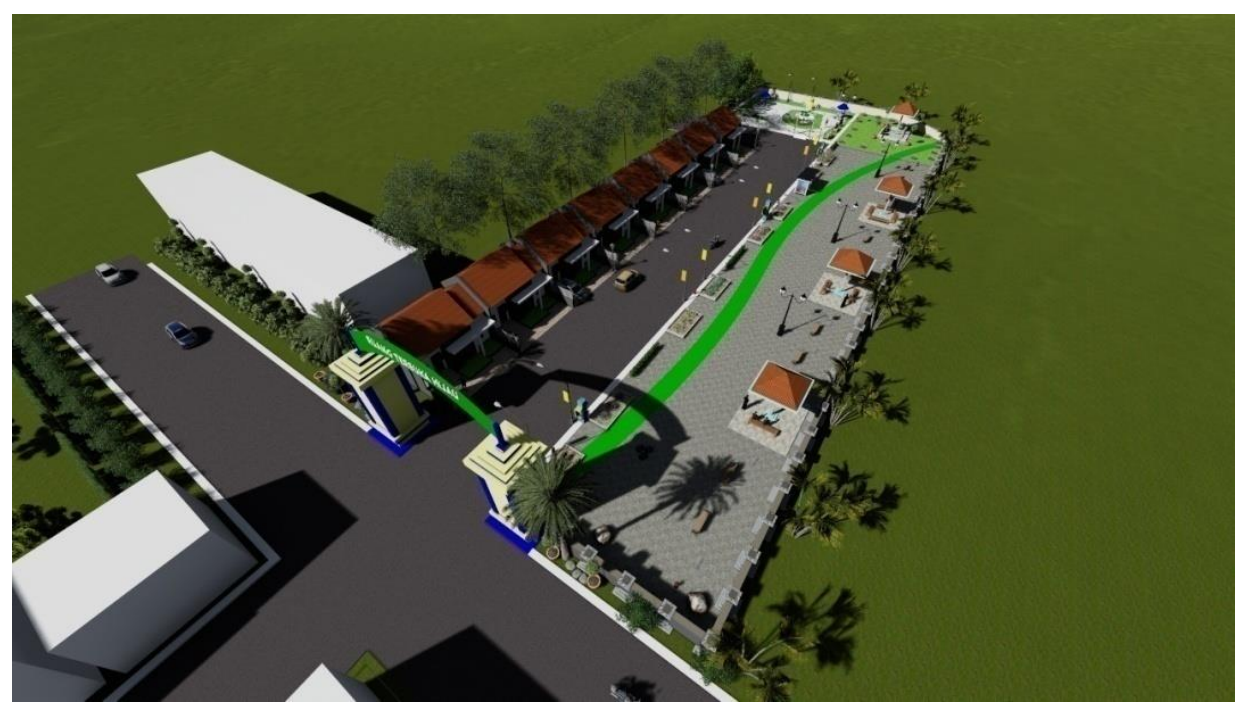

Gambar 4 Penempatan Objek

\subsection{PerancanganAntar Muka}

Perancangan antarmuka adalah gambaran dari animasi pemetaan kawasan RTH yang akan dibuat agar sistem yang nantinya akan dibuat lebih mudah dipahami
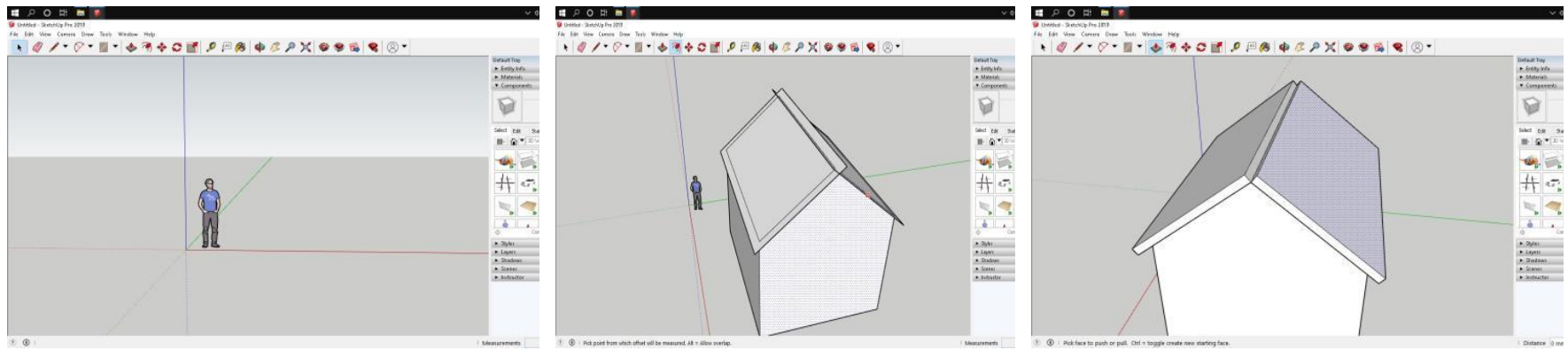

\subsection{Hasil Lumnion}

Gambar 5 Project baru

Aplikasi lumnion dijalankan maka tampilan yang pertama muncul yaitu gambar seperti diatas sehingga dapat memilih type viewport yang diinginkan.
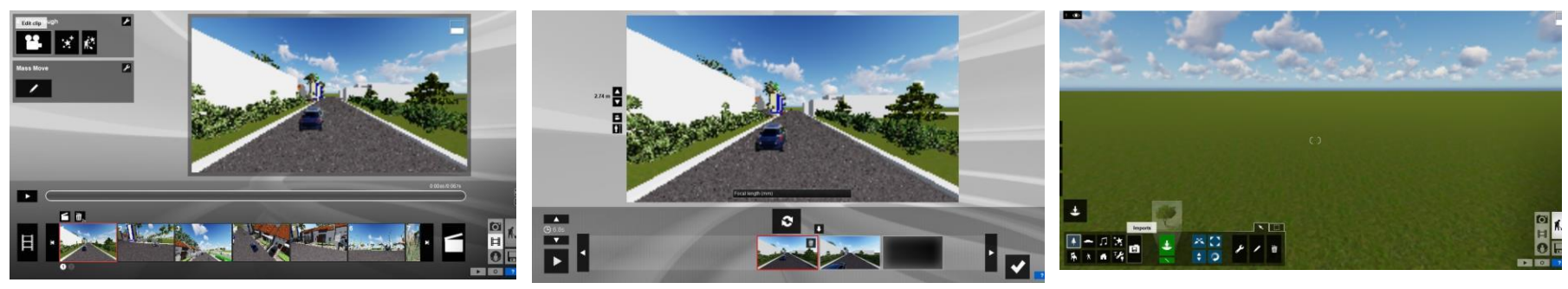

Gambar 6 Hasil Lumino

\subsection{Pengujian (Testing)}

Pengujian adalah proses pelaksanaan suatu program dengan tujuan menemukan kesalahan atau fungsi yang tidak sesuai dari tujuan pengembangan program yang dibuat, agar dapat dilakukannya perbaikan jika terdapat kesalahan.

Hasil Pengujian Pengujian yang akan animasi pemetaan kawasan dengan Skecthcup dan Lumnion. Pengujian akan dilakukan dengan menggunakan metode blackbox. 
Hasil pengujian dibuat untuk membuktikan serta memperlihatkan bahwa project yang dikembangkan sudah sesuai dengan tujuan pengembangan dan mampu memenuhi kebutuhan pengguna. Pengujian yang berdasarkan rencana pengujian menghasilkan hasil pengujian sebagai berikut

Tabel 1 Hasil Pengujian

\begin{tabular}{|l|l|l|l|l|l|}
\hline No. & \multicolumn{1}{c|}{ Data Uji } & \multicolumn{1}{c|}{ Input } & \multicolumn{1}{c|}{ Harapan } & \multicolumn{1}{c|}{ Output } & \multicolumn{1}{c|}{ Kesimpulan } \\
\hline 1. & Display video & $\begin{array}{l}\text { Pengamatan } \\
\text { langsung }\end{array}$ & $\begin{array}{l}\text { Video yang dit- } \\
\text { ampilkan sesuai } \\
\text { harapan baik dari } \\
\text { perancangan de- } \\
\text { sain maupun kuli- } \\
\text { tas video yang } \\
\text { dihasilkan }\end{array}$ & $\begin{array}{l}\text { Video animasi } \\
\text { kawasan yang } \\
\text { dihasilkan sudah } \\
\text { sesuai dengan } \\
\text { harapan }\end{array}$ & Valid \\
\hline 2. & Kualitas video & $\begin{array}{l}\text { Pengamatan } \\
\text { langsung }\end{array}$ & $\begin{array}{l}\text { Kualitas video } \\
\text { sudah HD dengan } \\
\text { format video Mp4 }\end{array}$ & $\begin{array}{l}\text { Video dengan } \\
\text { kualitas Mp4 }\end{array}$ & Valid \\
\hline
\end{tabular}

Setelah melalui proses Pra Produksi dan Produksi, maka proses selanjutnya adalah Pasca Produksi yaitu tahapan pengujian. Metode pengujian yang dilakukan adalah menjalankan video animasi yang sudah di render selanjutnya di play dengan tujuan untuk melihat apakah terdapat kesalahan pada objek-objek 3D, penempatan, tekstur, dan pergerakan kamera sebelum pada akhirnya masuk kedalam langkah terakhir yaitu finishing. Setelah lulus pada tahap pengujian, maka selanjutnya masuk kepada langkah finishing. Tahap ini dilakukan untuk memberikan elemen-elemen tambahan kedalam video animasi yang nantinya dipertunjukan, seperti penambahan suara, caption/text, bumper/intro dan koreksi warna. Setelah semua elemen dimasukkan, maka video tersebut kembali di render untuk menggabungkan seluruh elemen menjadi satu file yang memiliki ekstensi *.MP4.

\section{KESIMPULAN}

Berdasarkan hasil uraian penelitian diatas maka diambil kesimpulan sebagai berikut :

1. Perancangann animasi RTH dengan Sketchup dan lumnion Dapat mempermudah dalam perancangan RAB sebanyak $30 \%$

2. Berdasarkan data hasil uji t-test yang telah dilakukan, didapatkan bahwa nilai t tabel. 1,699127 maka -t.tabel $=-1,699127$. Sedangkan t.hitung adalah $-7,803$. Karena nilai -t.tabel $(-1,699127)>$ t.hitung (-7,803). Maka Ho ditolak Ha diterima. Berdasarkan hasil tersebut dapat dinyatakan bahwa Perancangann animasi RTH dengan Sketchup dan lumnion Dapat mempermudah dalam perancangan RAB sebanyak $30 \%$.

\section{DAFTAR PUSTAKA}

[1] Y. Syahfitri, “Teknik Film Animasi Dalam Dunia Komputer,” J. SAINTIKOM, vol. 10, no. 3, pp. 213-217, 2011.

[2] J. Angin, "Perancangan Animasi 3D Taman Kota Menggunakan Software 3DS Max Menggunakan Metode MDLC," J. Ilm. Core IT Community Res. ..., no. x, 2018, [Online]. Available: http://ijcoreit.org/index.php/coreit/article/view/110.

[3] D. Permana, "Pengembangan konsep taman kota tegal berdasarkan keinginan masyarakat," 2019.

[4] M. Pratama, A. Rachmansyah, and F. Usman, "Pemodelan Dinamis Kebutuhan Ruang Terbuka Hijau Kota Malang," Indones. Green Technol. J., vol. 5, no. 1, pp. 7-15, 2016.

[5] D. Priyanto, "Pengembangan Multimedia Pembelajaran Berbasis Komputer," vol. 14, no. 1, pp. 1-13, 2009.

[6] “2013 Vol. 6 No. 2 Juli - Desember PEMBELAJARAN MULTIMEDIA Jurnal Al-Ta’dib,” vol. 6, no. 2, pp. 84-98, 2013. 
JURSISTEKNI (Jurnal Sistem Informasi dan Teknologi Informasi) Vol 4, No.1, January 2022: Hal 9- 17 ISSN.

\section{$P: 2715-1875, E: 2715-1883$}

[7] P. Soepomo, "Pembuatan Film Animasi Pendek 'Dahsyatnya Sedekah' Berbasis Multimedia Menggunakan Teknik 2D Hybrid Animation Dengan Pemanfaatan Graphic," Pembuatan Film Animasi Pendek "Dahsyatnya Sedekah” Berbas. Multimed. Menggunakan Tek. 2D Hybrid Animat. Dengan Pemanfaat. Graph., vol. 1, no. 1, pp. 387-398, 2013, doi: 10.12928/jstie.v1i1.2554.

[8] 2013 Vol. 6 No. 2 Juli - Desember PEMBELAJARAN MULTIMEDIA Jurnal Al-Ta'dib, vol. 6, no. 2.2013.

[9] N. Imansari and P. Khadiyanta, "Penyediaan Hutan Kota dan Taman Kota sebagai Ruang Terbuka Hijau (RTH) Publik Menurut Preferensi Masyarakat di Kawasan Pusat Kota Tangerang,” vol. 1, no. 3, pp. 101-110, 2015, doi: 10.14710/ruang.1.3.101-110. 